Revista científico-académica internacional de Innovación, Investigación y Desarrollo en Diseño - ISSN 1889-433X

\title{
Arte, Revolución y Diseño
}

\section{Resumen}

El panorama actual europeo sintetizado en un siglo y medio de historia es el contexto previo y posterior a la Bauhaus, que atraviesa la Revolución Industrial y la Revolución Científica.

Una cincuentena de textos seleccionados da fe de las inquietudes revolucionarias, artísticas, éticas y estéticas de esta época que marcó nuestro pasado y abrió las puertas del presente.

Palabras clave: escuelas de Diseño, ideas sobre diseño, Bauhaus, arte, industria, revolución

\section{Art, Revolution and Design}

\section{Abstract}

The current European panorama synthesized in a century and a half of history is the context before and after the Bauhaus, that crosses the Industrial Revolution and the Scientific Revolution.

Some fifty selected texts attest to the revolutionary, artistic, ethical and aesthetic concerns of this era that marked our past and opened the doors of the present.

Keywords: Design schools, ideas about design, Bauhaus, art, industry, revolution 


\section{Bauhaus cumple 100 años.}

La escuela que cambió el arte y el diseño

inauguraba sus clases hace un siglo

en el mes de abril de 1919.

Esta recopilación es una mirada retrospectiva hacia las ideas que el diseño y sus tiempos suscitaron en sus mismos protagonistas y espectadores, actores de excepción. El diseño ha sido definido, considerado e interrogado una y mil veces y en todas las épocas. La bibliografía, las citas, son un buen reflejo de estas consideraciones. Por eso hemos traído aquí las voces diversas de quienes durante un siglo y medio han vivido los avatares intelectuales del arte, la revolución y el diseño, desde 1850 hasta 2000. Los pensamientos recogidos a continuación toman como eje central los tiempos de la Bauhaus, pero también sus pasos precedentes tres cuartos de siglo antes, y abarcan asimismo los ecos que resonaron hasta después de la escuela de Ulm. Una época convulsa, pero también apasionante y muy decisiva en la evolución del diseño.

Como veremos, en los textos prebauhausianos predomina el espíritu del arte y la estética con el trasfondo de la crítica marxista a la revolución industrial. En los escritos del Vhkutemas soviético prevalece el espíritu de la revolución proletaria y la subversión del arte coincidiendo con las vanguardias que han influenciado el diseño gráfico. Los textos del tiempo de la Bauhaus revelan la racionalidad funcionalista junto a la paradoja surrealista, y también la influencia decisiva de la lógica industrial. La escuela de Ulm fue el puente (inalcanzado) entre la era de la producción y la era de la información. Fue el paso del concepto de diseño gráfico al de diseño de comunicación visual.

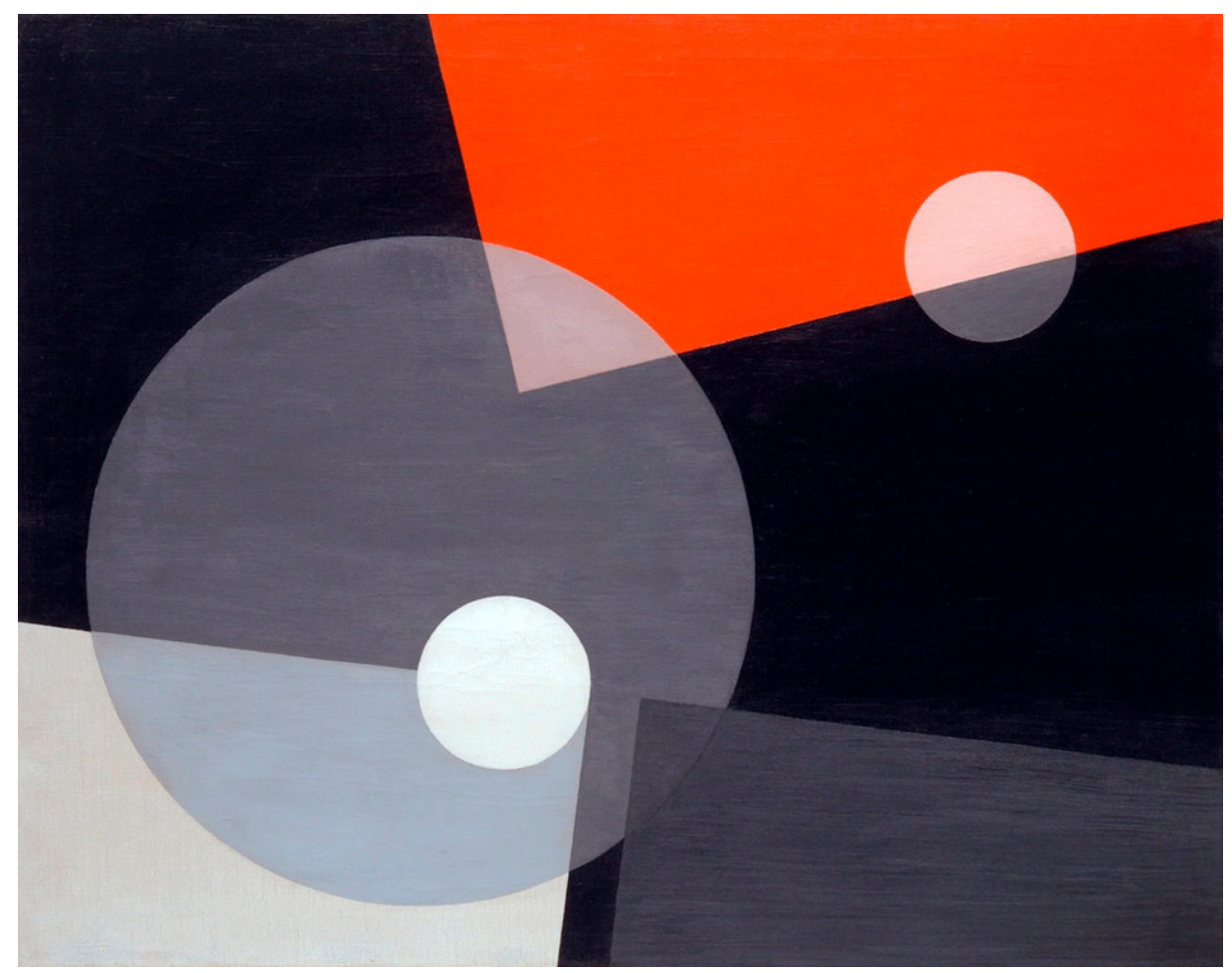

Laszlo Moholy Nagy, 1920 


\section{Resumen}

Años

1844

1863

1866

1895

1904

1909

1919

1920

1922

1923

1924

1925

1926

1927

1928

1936

1938

1940

1948

1949

1954

1958

1959

1963

1967

1968

1969

1970

1971

1972

1975

1983

1989

1992

1993

1999
Autores

Gryan/Marx

Toussant/Euric/David

Violett-le-Duc

Ruskin/Gorki

Souriau

Futuristas

Gropius

O. M. Brik

De Stijl

LEF Kouchner

LEF / Blok/Breton

Le Corbusier

Gropius

AKHRR

Mendelsohn/Meyer

Elmo Calkins

Havinden

Cleland

Wiener

Kepes/Burtin

Lustig

International situationniste

Golden/Lubalin

Mathieu

Garland

Dubuffet/Reich

Moholy-Nagy

Moles

Moles/Bonsiepe

Marx

Marc Le Bot

Vignelli

Ricard

Quarante

Manzini

Flusser
Épocas

Revolución Industrial

Bauhaus/Vhkutemas

Revolución Científica 
"Cuanto menos una máquina sea representativa de la fuerza exterior que la mueve, más valor estético tendrá. La máquina que más se parezca a un ser vivo será la más Bella".

$$
\text { Jean-Marie Gryan, } 1844
$$

"El hombre se apropia su ser universal de una manera universal, es decir, en tanto que hombre total. Cada una de sus relaciones humanas con el mundo, la vista, el oído, el olor, el gusto, el tacto, el pensamiento, la contemplación, el sentimiento, la voluntad, la actividad, el amor, en fin todos los órganos de su individualidad, igual como los órganos que, en su forma, son inmediatamente órganos sociales, están en su comportamiento objetivo o en su relación con el objeto, la apropiación de éste, la apropiación de la realidad humana; su relación con el objeto es la manifestación de la realidad humana".

Karl Marx, Manuscritos de 1844

En 1863, Toussant, Bernard Euric y David, hablaban de "las artes de la industria comercial"

Histoire de la Peinture au Moyen Age

"En el punto en que debemos situarnos, no considerando más que la cuestión de arte, lo bello, el estilo no residen en una sola forma, sino en la armonía de la forma en vistas de un objeto, de un resultado. Si la forma indica netamente el objeto y da a entender con qué fin ese objeto fue producido, esta forma es bella, y es por esto que las creaciones de la naturaleza son siempre bellas para el observador. La justa aplicación de la forma al objeto y a su uso o su función; la armonía que preside siempre esta aplicación nos llena de admiración ante un roble como ante el más pequeño insecto. Nosotros encontramos estilo en el mecanismo de las alas del ave de presa, igual como lo encontramos en las curvaturas del cuerpo de un pez, porque el estilo surge claramente de este mecanismo y de estas curvas tan bien trazadas que por esto uno vuela y el otro nada. No nos importa mucho, después de esto, que vengan a decirnos que el pájaro tiene alas para volar, o que vuela porque tiene alas".

Eugène-Emmanuel Violett-le-Duc, 1866

"La proa de un barco es ingenuamente perfecta". 
"La estética es la moral del futuro".

Máximo Gorki, 1895

"Lo bello y lo útil pierden igualmente si son separados. Partiendo de este principio de que son dos cosas absolutamente distintas e independientes, cada una ha sido destinada a su dominio. Una industria sin ninguna preocupación hacia el arte y la belleza, un arte desdeñoso de todas las realidades de la vida, he aquí el resultado de esta separación de géneros. Estamos empezando, por suerte, a regresar de este prejuicio. Me parece bien que asistamos, en este momento, a la reconciliación de la industria y del arte; las dos ideas de lo útil y lo bello, indebidamente separadas, tienden a unirse de nuevo en nuestro espíritu (...). No puede haber conflicto entre lo bello y lo útil. El objeto posee su belleza desde el momento que su forma es la expresión manifiesta de su función".

Paul Souriau, La beauté rationelle, Paris: Alcan, 1904

"Declaramos que el esplendor del mundo se ha enriquecido con una nueva belleza: la belleza de la velocidad. Un coche de carreras ornado con gruesos tubos como serpientes de explosivo aliento... un coche rugiente, que parece correr sobre metralla, es más bello que la Victoria de Samotracia (...).

Queremos demoler los museos, las bibliotecas, combatir el moralismo, el feminismo y todas las bajezas oportunistas y utilitarias".

Manifiesto del Futurismo, Italia, 1909

"Con la convicción con que debemos utilizar la revolución política para liberar el arte de décadas de reclutamientos, un grupo de artistas y amantes del arte unidos en una misma perspectiva, se ha formado en Berlín. El grupo se esfuerza en obtener la reunión de todas las energías esparcidas y divididas que, más allá de proteger intereses profesionales particulares, intentan unirse para reconstruir el conjunto de nuestra vida artística.

En contacto estrecho con otras asociaciones que trabajan en el mismo sentido a través de Alemania, el Arbeitsrat für Kunst espera, en un próximo futuro, alcanzar los objetivos expuestos en el programa siguiente: He aquí como preámbulo los principios directores:

- el Arte y el pueblo no han de ser sino uno,

- el Arte ya no debe estar reservado a la élite, sino que debe ser la vida y la felicidad de las masas,

- nuestra finalidad es la unión de todas las artes bajo el ala de la gran arquitectura". 
"El don de la imaginación es siempre más importante que la técnica, que se adapta siempre a la voluntad creativa del hombre".

Walter Gropius, 1919

"Hace falta:

1) Recortar seriamente la parte "pura" del Vkhutemas y ampliar la parte industrial.

2) Reunir las facultades industriales e insertar las del grafismo.

3) Reorganizar la facultad del grafismo insertándole las secciones sociales del arte: cartel, caricatura, ilustración, sátira, etc.

4) Ligar el Vkhutemas a los centros de producción nacional y de formación política.

5) Organizar en el seno del Vkhutemas el principio de encargos exteriores que permitan el trabajo práctico.

6) Situar los "constructivistas" al mismo nivel que los "artistas puros" librándoles un diploma de "ingeniero-artista".

O. M. Brik, Extractos de escritos del Vkhutemas², Moscú, 1920.

"Exigimos:

1) el fin de las exposiciones. Reclamamos en su lugar salas de demostración para obras colectivas.

2) Un intercambio internacional de ideas sobre los problemas de la creación.

3) El desarrollo de los medios universales de creación para todas las artes.

4) El fin de la división entre el arte y la vida (el arte es la vida).

5) El fin de la división entre el artista y el hombre".

De Stijl, 1922, en: De Stijl (1921-1932) Complete Reprint

A pesar de la ausencia de medios, el esfuerzo de los designers soviéticos fue infinitamente más grande, más audaz y más ligado a los objetivos políticos del país que el de sus colegas contemporáneos occidentales (Bauhaus) que trabajaban en el marco de una sociedad burguesa. Para los soviéticos, en esta época, no se trataba tanto de vivir mejor en el sentido estrecho cuantitativo del término, sino de vivir de otro modo:

"iFuturistas!

Vuestros méritos en el arte son grandes. Pero no creáis que podréis aprovecharos de vuestra acción revolucionaria de ayer. Hoy, en vuestro trabajo, mostrad que vuestra explosión no es un alarido incesante de una inteligencia estrangulada sino un combate, un trabajo, codo con codo, con todos aquellos que se lanzan adelante por la victoria de la causa común. 


\section{¡Constructivistas!}

Temed convertiros en una simple escuela estética del arte. El constructivismo, si no es más que arte, no es nada. El problema de la existencia misma del arte está planteado. El constructivismo debe ser una suerte de "ingeniería formal superior" de toda la vida (...). Nuestras ideas deben desarrollarse apoyándose en las cosas actuales.

\section{¡Productivistas!}

Temed convertiros en artesanos, consagrados al arte aplicado. Aprended al lado de los trabajadores. Dictando desde vuestros despachos órdenes estéticas a las fábricas, seréis sus simples clientes. Vuestra Escuela: la fábrica".

LEF, Moscú, núm. 1, marzo 1923

Los constructivistas anuncian su programa en la revista que se convertirá en el órgano a cuyo alrededor se agruparán escritores y poetas, pero también teóricos del arte, arquitectos y estos artistas que, desde ahora, renuncian al arte puro y quieren ser "ingenieros del arte", "artistas productivistas". En LEF no 1 escriben:

"EI LEF llevará a cabo una acción de agitación al servicio de las artes abriendo al arte la ruta hacia el mañana.

EI LEF llevará en el seno de las masas una acción de agitación por los medios de nuestro arte encontrando en ellas su fuerza organizacional.

EI LEF apoyará nuestras teorías por un arte eficaz elevándolo al nivel más alto de calificación profesional.

EI LEF se batirá por un arte de construcción de la vida".

$\mathrm{Y}$, definiendo desde este primer número el frente principal en el cual se baten, escribirán: "Nos hemos batido contra el antiguo modo de vida. Nos batiremos hoy contra los restos de este modo de vida".

Los constructivistas se adhieren totalmente a los objetivos de la revolución. Piensan que el arte puede ser uno de los instrumentos de la transformación social. Y proclaman: "El modo de vida es nuestro nuevo frente. El arte, nuestra arma en este frente".

LEF, Moscú, núm. 1, marzo 1923

"Los ingenieros-constructores son los inventores de las cosas, los organizadores de los materiales, los obreros de la forma. El dominio de su actividad es en principio el mismo que el del pintor-inventor. Es por esto que, por sus medios fundamentales y sus métodos de trabajo, los artistas podrían desde hoy, y con bastante éxito, tomar el lugar de los ingenierosconstructores. Bastaría con que adquieran los conocimientos útiles, necesarios para la construcción industrial. Dicho de otro modo, deberían convertirse en ingenieros-artistas.

Aquí no hay sitio para una evolución normal. Sólo la revolución puede arrastrar una transformación".

Boris Kouchner, LEF, Moscú, núm. 3, junio-julio 1923 
"Y los ingenieros? Por supuesto, ellos han construido y construyen. Construyen sólidamente, de una forma moderna, apoyándose en la técnica más reciente. Pero, cosa extraña, mientras se ocupan de sus propios problemas (puentes, grúas, andenes), todo va bien. Sin embargo, basta con que aborden sujetos más generales, para que, detrás de la máscara del ingeniero, asome el antiguo rostro bien conocido del esteta. Educado según los cánones del arte burgués, el ingeniero es casi siempre un fetichista, como el arquitecto".

LEF, Moscú, 1923

En el no 4 del LEF, en 1924, escriben:

"Durante por lo menos la próxima decena de años, la producción soviética tendrá que contentarse con las artes aplicadas, única posibilidad teniendo en cuenta el nivel técnico de la mayor parte de nuestras fábricas. Y la cuestión es ésta: ¿bajo qué forma se presentarán los productos realizados? ¿Nos da verdaderamente lo mismo saber qué estética propagarán los objetos usuales del modo de vida obrero? (...). El problema se plantea pues así: o bien cultivar el arte burgués reaccionario y retrógrada, o bien, en la medida de nuestras fuerzas, construir nuestro propio arte revolucionario Y QUE PREFIGURA EL MODO DE VIDA FUTURO AL MISMO TIEMPO QUE SE CONSTRUYE EL EDIFICIO SOCIAL; o bien quedarse sentados con los brazos cruzados, suspirar por el futuro y esperar a que llegue hundiéndose en el pantano de la estética pequeño-burguesa, o bien construir nuevas formas a partir de los problemas que plantea la edificación proletaria".

"En lugar de inspiración y de contemplación estética, nosotros preconizamos una voluntad de creación consciente, exigente de claridad y de precisión en las formas -la vida contemporánea ha puesto en el primer rango el problema de la economía-.

- La ley de economía produce una simplificación extrema de los medios de expresión.

- El trabajo manual, que caracteriza las diferencias grafológicas de cada artista, hace que la producción mecánica represente la expresión positiva de las formas.

- El método de la mecanización está ligado directamente a los productos técnicos.

- Los fines de la técnica son tan importantes como los de la estética.

- Nos encontramos ante el problema de la estética de la economía a ultranza".

Manifiesto de la revista polaca Blok, 1924 (extracto)

"Nosotros vivimos todavía bajo el reinado de la lógica, he aquí a lo que voy. Pero los procedimientos lógicos, en nuestros días, no se aplican más que a la resolución de problemas de interés secundario. El racionalismo absoluto que está de moda no permite considerar más que hechos que proceden estrechamente de nuestra experiencia. Los fines lógicos, por el contrario, se nos escapan (...). Bajo color de civilización, bajo pretexto de progreso, hemos llegado a desterrar del espíritu todo lo que se puede acusar, con razón o no, de superstición, de quimera; a proscribir todo modo de búsqueda de la verdad que 
no sea conforme al uso.

La imaginación está, quizás, en el punto de retomar sus derechos. Si las profundidades de nuestro espíritu encierran extrañas fuerzas capaces de aumentar las de la superficie, o de luchar victoriosamente contra ellas, para someterlas en seguida, si hay lugar, al control de nuestra razón. Con eso, los analistas tienen las de ganar".

André Breton, Manifestes du surréalisme, 1924

"En otro tiempo, el objeto decorado era raro y costoso; hoy es innumerable y barato. En otro tiempo, el objeto simple era innumerable y barato; hoy, es raro y caro. Antaño, el objeto decorado era un elemento de ostentación: el plato familiar de campesino que se colgaba en la pared, el chaleco bordado de los días de fiesta, los utensilios presuntuosos de los príncipes. Hoy, el objeto decorado inunda los anaqueles de los grandes almacenes; se vende barato a las modistillas. Si se vende barato es porque está mal fabricado y la decoración oculta las taras de su fabricación y la mala calidad de los materiales: el decorado camufla".

"Una actitud nueva hacia el diseño que se define como sigue: la resuelta afirmación del entorno viviente de las máquinas y de los vehículos; un diseño orgánico de los objetos basado en sus propias leyes contemporáneas sin guiños románticos ni desperdicio. Una limitación tiene características como las formas y los colores primarios inmediatamente accesibles a todos. La simplicidad en la diversidad, una utilización económica del espacio, del material, del tiempo y del discurso.

Utilizando los métodos modernos y económicos de estandarización (producción masiva por la industria) y la venta a gran escala, los productos salidos de los prototipos realizados por la Bauhaus pueden ser ofrecidos a precios razonables.

En estos laboratorios, la Bauhaus quiere formar un nuevo tipo de colaboradores para la industria y el artesanado que serán capaces de dominar la tecnología y la forma".

Walter Gropius, Principles of Bauhaus production, Dessau, 1926

"Nosotros, artistas de la revolución proletaria, tenemos el deber de transformar la realidad revolucionaria auténtica en formas realistas, comprehensibles para las grandes masas de trabajadores, y de participar activamente con nuestro trabajo artístico y social a la construcción del socialismo".

Extraído de las declaraciones de la AKHRR (Asociación de artistas revolucionarios de Rusia), 1927 
"La mecanización no transformará más el espíritu humano. Al contrario, la sumisión planificada de las fuerzas naturales al servicio del hombre creará las bases necesarias a la economía y a la política. La sociedad y la cultura crecen a partir de la economía. El hombre ya no es, pues, el pequeño accesorio automático de la máquina. Él es su creador, su dueño. Es por el dominio total de sus deseos que liberará los componentes místicos de su naturaleza vueltos hacia el misterio. La esperanza del mundo nuevo tiene por señal una magnífica combinación.

Rusia y América. Lo colectivo y lo individual. América y Rusia. Lo terrestre y lo divino".

Erich Mendelsohn, Síntesis, Berlín, 1928

"Toda cosa en este mundo es el producto de la fórmula: función x economía. Estas cosas no son obras de arte: todo arte es composición y por consiguiente antifuncional. Toda vida es función y por consiguiente no artística. ¿La idea de la "composición de un puerto"? Risible. Pero, ¿cómo se concibe un plano de urbanismo? ¿O el plano de una vivienda? ¿Composición o función?”.

Hannes Meyer, extraído de Construir, Bauhaus, 1928

"La escala más alta de excelencia del arte publicitario se alcanza en las páginas de las revistas. En Estados Unidos no contamos con carteles como los que, por lo común, se ven en Europa debido a varios motivos. El primero es la forma y el tamaño de nuestras carteleras en la vía pública: en vez del soporte más pequeño y mejor proporcionado que se usa en Europa, tenemos un soporte grande y oblongo que no se presta al buen diseño. Además, por algún motivo, en el diseño de carteles no se emplea la misma libertad de expresión, la misma audacia y originalidad que se manifiesta en los anuncios de las revistas".

Earnest Elmo Calkins, 1936

"La expresión visual me parece la mejor descripción del trabajo del diseñador en el área de la publicidad y la propaganda. Su tarea es comunicar ideas al público en términos de imágenes y palabras. Su problema es crear formas visuales que constituyen una amalgama de las dos cosas y que sean apropiadas para su multiplicación a través de la imprenta".

Ashley Havinden, 1938

"Todo el arte fue moderno cuando se hizo, y lo sigue siendo si se adecua a la vida como la vivimos ahora; y busco en vano algún arte aplicado digno de ese nombre que no haya sido también funcional en algún sentido. ¿Y qué significa el término 'funcionalismo'? ¿Acaso un diseño no debe estar relacionado con ninguna función excepto las mecánicas y las materiales? ¿No es posible que 
las obras más fantásticas hayan sido funcionales en cuanto expresaban el espíritu y se adecuaban perfectamente a la vida para la que debían servir?"

T. M. Cleland, 1940

"La información es información, no es materia ni energía".

Norbert Wiener, 1948

“¿Cuál es la función en el diseño? ¿Cuál es el propósito del diseño hecho por el hombre? ¿Basta con responder que el propósito de un edificio es dar refugio, que el propósito de una silla es sostener el cuerpo humano, que el de un libro es permitir que se lo lea? ¿Pueden entenderse tales funciones sólo dentro del estrecho radio de lo que consideramos que es su función, o es necesario que indaguemos más aún hasta llegar a la raíz común y definitiva de todos esos propósitos?"

György Kepes, 1949

"Las comunicaciones visuales se basan en cuatro realidades principales:

- la realidad del hombre, como medida y medidor

- la realidad de la luz, el color, la textura

- la realidad del espacio, el movimiento, el tiempo

- la realidad de la ciencia".

Will Burtin, 1949

“¿Qué es un diseñador? El director de arte de una agencia se aboca al diseño publicitario contando con un marco específico de investigación de mercado, con los problemas concretos del cliente, etc., etc., etc. Es posible que todos esos estudios que mantienen la publicidad en funcionamiento demuestren algo, pero lo dudo. Lo único que prueban es que, por algún motivo que todavía no se descubrió, parece que un anuncio publicitario tiene éxito o no. No demuestran que los anuncios bien diseñados no funcionan. No demuestran que los anuncios con menos texto no funcionan. No demuestran que todos los anuncios tipográficos no funcionan. En lo que respecta al diseño de anuncios, no creo que haya algo que demuestren las investigaciones y los estudios".

Alvin Lustig, 1954

"Contrariamente a lo que piensan los funcionalistas, la cultura se sitúa allí donde acaba lo útil. La ausencia de cultura, ¿no la sentimos penosamente hoy en la miseria de las televisiones y de los scooters? Una revolución en la vida precede a una revolución en el arte". 
"Si es que en realidad existe la Nueva Tipografía Estadounidense, sin duda habla con acento extranjero. Y probablemente hable demasiado. Gran parte de lo que dice es obviamente un disparate. Muchas veces suena tan pomposo que parece un disparate, aunque si uno escucha con detenimiento no lo es... del todo. Simplemente es complicado hasta el exceso. Cuando se lo traduce al idioma anterior a la guerra, no es más que obvio".

William Golden, 1959

"Es necesario experimentar con nuevas formas gráficas en publicidad. Uno de los resultados de tal experimentación es lo que prefiero denominar 'la imagen tipográfica"' (...) "Cuando componemos una ilustración tipográfica, tal como cuando componemos una buena fotografía o ilustración, hace falta una estrecha unidad de elementos. Por lo tanto, hemos tenido que tomarnos libertades respecto de las muchas reglas tradicionales que lograron imponerse como criterios de la buena tipografía. Esas desviaciones -a saber: medidas más amplias, eliminación del interlineado, supresión del espaciado entre las letras y alteración de las formas tipográficas- han despertado reacciones violentas por parte de los tipógrafos y diseñadores tradicionales para quienes tales reglas son sagradas".

Herb Lubalin, 1959

"Ya se trate de un automóvil, una butaca, una lámpara, un aparato telefónico o un tenedor, la política de nuestros fabricantes siempre es la misma. Prisioneros entre las trampas de la rutina y el deseo de seducir por la novedad, el industrial hoy convoca para la elaboración de las formas de sus productos a diseñadores-conceptistas, que no tienen la misión de crear, sino de buscar el compromiso rentable entre las formas de una vanguardia cuya audacia podría asustar a la clientela y aquellas otras formas a las cuales esta clientela está benévolamente habituada. El único criterio es la rentabilidad falsamente calculada sobre lo que se supone que es el gusto del público, que se infravalora".

Georges Mathieu, 1963

"El engañoso eslogan El medio es el mensaje implica que los que trabajamos en los medios masivos de comunicación ahora podemos tratar con condescendencia y superioridad el contenido inicial que se nos presenta, a sabiendas de que, por trivial que sea, lo transformaremos en significativo: de hecho, podemos alegrarnos por la trivialidad en tanto representa un desafío a nuestro talento. Eso es pura charlatanería".

Ken Garland, 1967 
"Habría que enseñar en las escuelas a cuestionar todas las ideas recibidas, todos lo valores reverenciados, denunciar todos los mecanismos de nuestro pensamiento donde el condicionamiento cultural interviene sin que nos demos cuenta, se limpiaría así la maquinaria de la mente hasta su desoxidación integral. Se vaciarían así las cabezas de todo el fárrago que las embotella; se desarrollaría metódicamente y por medio de ejercicios apropiados, la vivificante facultad de OLVIDAR".

Jean Dubuffet, Asphyxiante culture, 1968

"El objetivo de una revolución cultural es el desarrollo en los individuos de una estructura psíquica que los haría capaces de autonomía".

Wilheim Reich, La Révolution sexuelle, 1968

"El diseño no es una profesión, es una actitud. El diseñador debe saber que las características internas y externas de una silla, una mesa, una máquina, un cuadro o una escultura, no son disociables. Las nociones de diseño y de diseñador deben ser transformadas. Hay que abandonar el concepto de "especialista" para alcanzar una actitud operacional global de ingenuidad y de innovación que permita captar los proyectos en sus relaciones con las necesidades de los individuos y de la sociedad, más que aisladamente. Hay diseño en la organización de nuestra afectividad, en nuestra vida familiar, en las relaciones sindicales, en el urbanismo como en todo trabajo que reúne individuos "civilizados". Finalmente, todos los problemas de diseño están fundados en una única preocupación: "el diseño para la vida".

"Todo eso implica que no hay jerarquía entre las artes, la pintura, la fotografía, la música, la poesía, la escultura, la arquitectura y otras actividades tales como la creación industrial. Cada una de ellas puede ser en efecto el punto de partida de una fusión en el diseño de la función y de la significación".

L. Moholy-Nagy en Vision in Motion, Chicago, 1969

"El diseñador no es un artista. El diseñador es un ingeniero del entorno, es responsable del envoltorio (cárter, forma generalizada, interfaz, terminal) y es el abogado del conjunto de los utilizadores cerca de la producción. El diseñador es un demiurgo modesto: constructor e intermediario de la relación del hombre con el entorno artificial. El diseñador aporta su rigor al mundo tecnológico igual como a la futilidad del consumo. El diseñador es fundamentalmente creador aplicado, creador intermediario entre la invención y el objeto".

Abraham Moles, 1970 
"El principio del funcionalismo quiere que los objetos sean rigurosamente determinados por su función. Él introduce una idea de rigor, de disciplina y, por eso mismo, de ascetismo y propone una religión al arte contemporáneo de 1930 a 1950".

Abraham Moles, Le Kitsch: l'art du bonheur, Paris 1971

"En el centro de la tendencia 'Bellas Artes' brilla el individuo creador egocéntrico. Es así que se olvida fácilmente el complemento social de quien crea, a saber el usuario. El diseñador no debe buscar proyectar su personalidad en el diseño, sino que debe preocuparse de la función asumida por el objeto creado en la sociedad y el uso que hará de él esta misma sociedad".

Guy Bonsiepe, "Prémises pour le design et le sous-developpement", en L'architecture d'au-jourd'hui, 1971

"La producción no ofrece solamente un objeto material a la necesidad, ella ofrece también una necesidad al objeto material (...). La producción no produce solamente un objeto para el sujeto, sino también un sujeto para el objeto".

Karl Marx, Contribution à la critique de l'économie politique, Paris: Editions Sociales, 1972

"Bajo todas las formas que la primera revolución industrial ha podido tomar sucesivamente ("artes aplicadas", "artes decorativas", "diseño"), la cuestión de las relaciones entre arte y técnica reenvía al proceso de la división del trabajo, de abstracción y de racionalización crecientes de las prácticas humanas, que ha permitido al modo de producción capitalista reforzar su sistema económico, político, ideológico, extendiendo a todos los sectores de la práctica la ley de la productividad".

Marc Le Bot, Art/Design, 1975

"No es de sorprender que, junto con la falta de historia y de teoría, la crítica esté ausente por completo del diseño. La función principal de la crítica no es la de hacer comentarios obsequiosos o bien denigrantes sino la de ofrecer interpretaciones creativas de la obra, periodo o teoría que es objeto de análisis" (...) "Con la crítica, los diseñadores contarán con la posibilidad de hacer una lectura múltiple de la obra de otros diseñadores o con la oportunidad de concentrarse en el significado de movimientos expresivos particulares. La crítica impedirá en gran medida la difusión superficial de modas transitorias, o en cualquier caso, ofrecerá una base para evaluarlas en el contexto adecuado. El diseño gráfico no será una profesión hasta que no contemos con la crítica". 
"La insistencia con que se tildan de diseño a las más atrevidas creaciones de mobiliario o de moda, han ido confiriendo a este término una connotación frívola que nada tiene que ver con el papel que, históricamente, le corresponde a esta nueva disciplina creativa. Las insolentes creaciones de cierto 'diseño' que abundan en revistas y exposiciones no son auténtico diseño; son sólo escaramuzas superficiales y engañosas".

André Ricard, 1989

"Para el público, la palabra diseño lleva a un desprecio, a un malentendido".

Danielle Quarante, 1992

"Todo objeto producido por el hombre es la materialización de algo pensableposible; esto es, algo que alguien ha podido pensar y que al mismo tiempo podía ser realizado. Se sitúa en el punto de intersección entre las líneas de desarrollo del pensamiento (modelos mentales, estructuras culturales, formas de conocimiento) y las del desarrollo técnico (disponibilidad de materiales, técnicas de transformación, sistemas de previsión y control). Esta interacción entre 'pensable' y 'posible', a la que damos el nombre de proyecto, no es simple ni lineal: no es un amplio y libre 'pensable' que simplemente debe restringirse dentro de los límites de lo 'posible', porque el conocimiento de estos mismos límites es un elemento constitutivo de aquello que puede ser pensado".

Ezio Manzini, La materia de la invención, 1993

"La mirada del diseñador es la de un tercer ojo (a saber, un ordenador) gracias al cual puede intuir y manejar eternidades. Luego puede programar a un robot para que transfiera esa eternidad, así intuida y manipulada, a la temporalidad (por ejemplo, para que cave canales o construya cohetes). En Mesopotamia la llamaban profeta. Merece más bien el nombre de Dios. Pero gracias a Dios no es consciente de ello y cree ser un técnico o un artista. Que Dios le conserve esa fe".

Vilém Flusser, "The Shape of Things", 1999 


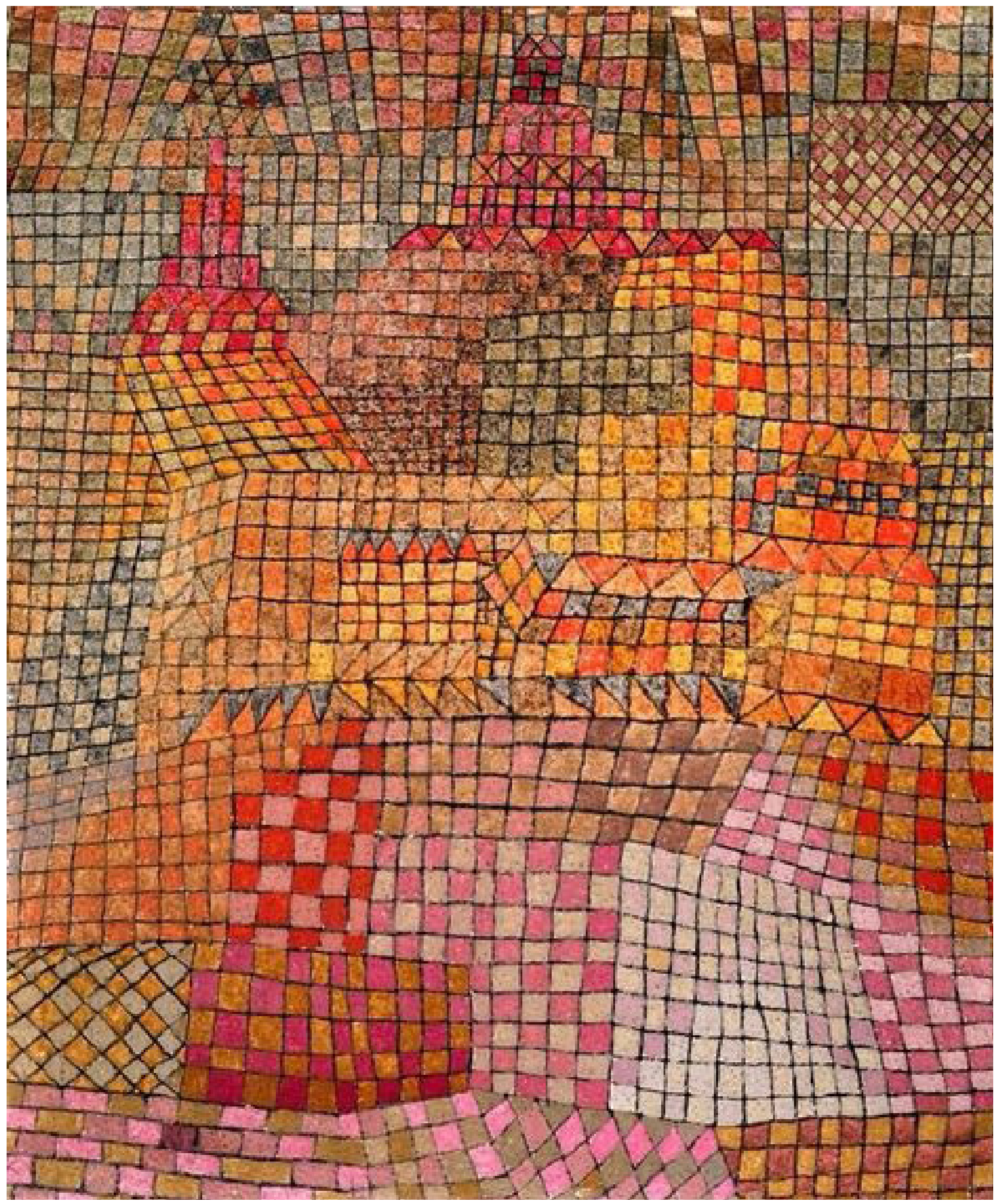

Paul Klee, 1932 